\title{
Challenges for Engineering Design, Construction, and Maintenance of Infrastructure in Afghanistan
}

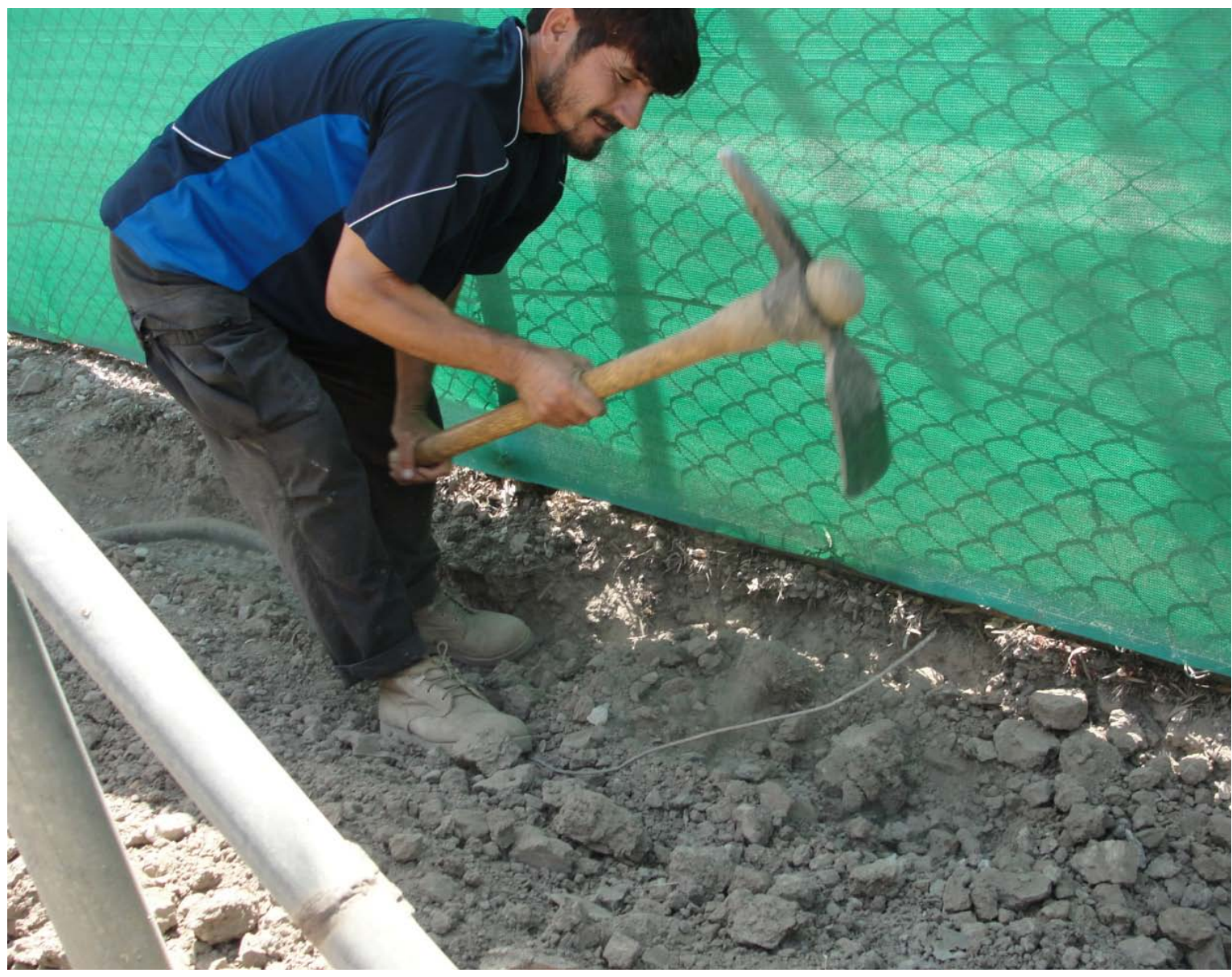




\title{
Challenges for Engineering Design, Construction, and Maintenance of Infrastructure in Afghanistan
}

\author{
Rosa T. Affleck \\ Cold Regions Research and Engineering Laboratory \\ U.S. Army Engineer Research and Development Center \\ 72 Lyme Road \\ Hanover, NH 03755 \\ Reed Freeman \\ U.S. Army Engineer District, Afghanistan \\ Qalaa House, Kabul, Afghanistan \\ APO AE 09356
}

Final report

Approved for public release; distribution is unlimited.

$\begin{array}{ll}\text { Prepared for } & \text { U.S. Army Corps of Engineers } \\ & \text { Washington, DC 20314-1000 }\end{array}$ 
Abstract: Western nations, particularly the United States, may not have the most applicable construction techniques for rebuilding infrastructure in other countries. Afghanistan, for example, does not have welldocumented engineering design and construction standards. The U.S. forces and Government agencies arrived in Afghanistan anticipating that construction funded by the U.S. would meet the Continental United States (CONUS) level of standard practice. Similarly, other well-developed countries arrived in Afghanistan with the intention of using their country's adopted construction standards. Both U.S. and international construction standards may appear logical to use for this purpose. However, it is often difficult, and many times impossible, to meet traditional U.S. engineering design and construction standards in post-conflict areas owing to limitations that include: a scarcity of high-quality materials and construction equipment, a lack of understanding of the terrain and environment, a lack of awareness of available local skills, a lack of skilled labor, and poor socioeconomic conditions. A more deliberate and holistic approach is needed in which we consider and integrate the host nation's capabilities and understand their limitations. The majority of infrastructure projects in postconflict countries are mission-specific. In most cases, once constructed and operational, very little emphasis is given addressing maintenance issues. Site-specific and culturally sustainable guidance for maintenance must be implemented as a part of the design process and incorporated into training programs to ensure sustainable, long-term performance or service life of the infrastructure. This ensures leaving behind transportation, buildings, water, and other infrastructure that the host country is capable of managing and maintaining.

U.S. Army Corps of Engineers (USACE) has successfully supported the Combatant Commands for engineering solutions by managing both engineering and construction projects, environmental restoration, and other projects. The USACE Engineer Research and Development Center (ERDC) possesses a unique combination of basic research and applied engineering expertise that collectively can solve challenging infrastructure problems. USACE-ERDC's researchers and engineers are field capable, having conducted projects on every continent, and are experienced in providing unique, adaptable solutions in austere locations with limited resources. 
DISCLAIMER: The contents of this report are not to be used for advertising, publication, or promotional purposes. Citation of trade names does not constitute an official endorsement or approval of the use of such commercial products. All product names and trademarks cited are the property of their respective owners. The findings of this report are not to be construed as an official Department of the Army position unless so designated by other authorized documents.

DESTROY THIS REPORT WHEN NO LONGER NEEDED. DO NOT RETURN IT TO THE ORIGINATOR. 


\section{Table of Contents}

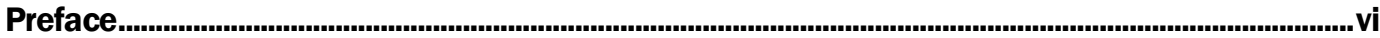

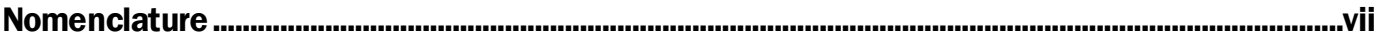

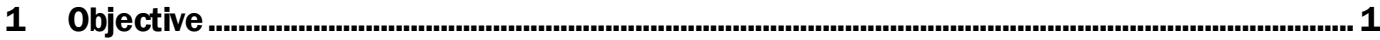

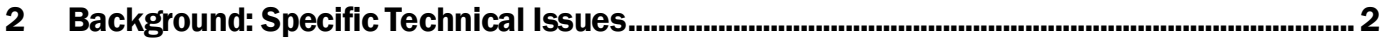

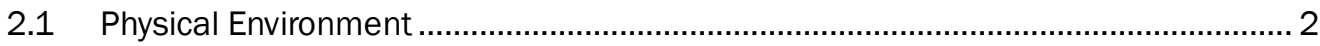

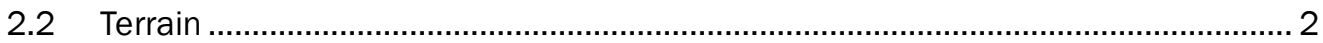

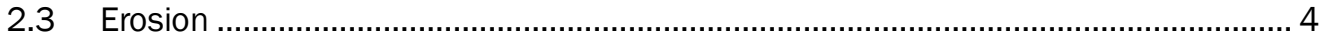

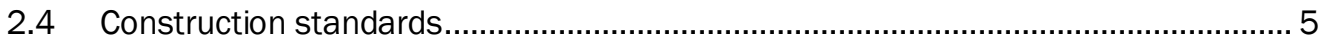

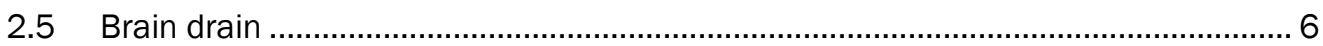

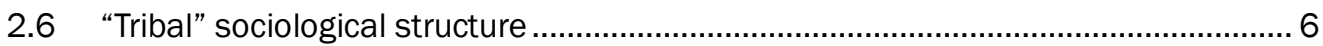

2.7 Difficulties in reaching projects for Quality Assurance/Quality Control

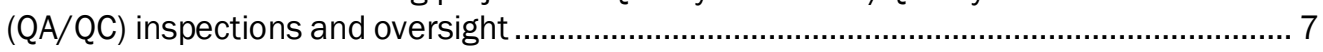

2.8 Security considerations and strategic design for construction.................................. 7

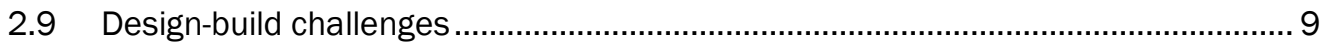

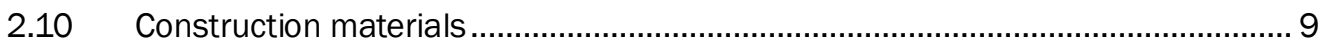

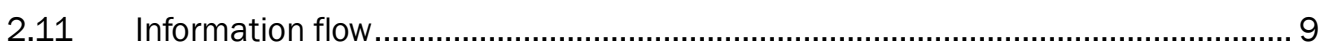

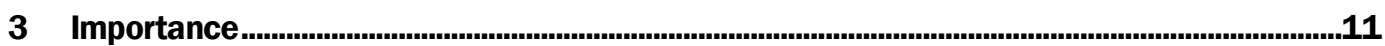

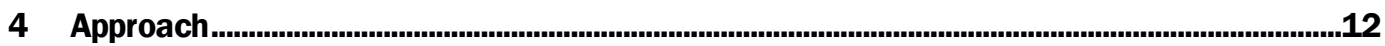

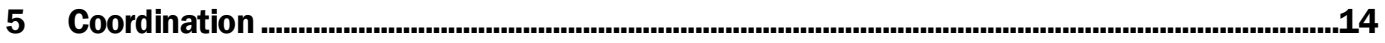

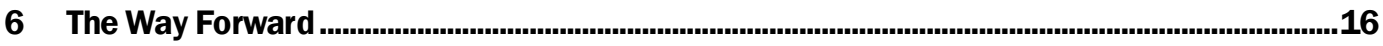

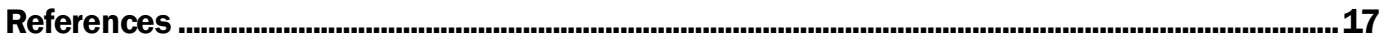

Report Documentation Page 


\section{List of Figures}

\section{Figures}

Figure 1. Trails are common in mountainous remote areas in Afghanistan. ........................................

Figure 2. Roads used by U.S. forces. .................................................................................................

Figure 3. Road washed out during the wet season............................................................................... 4

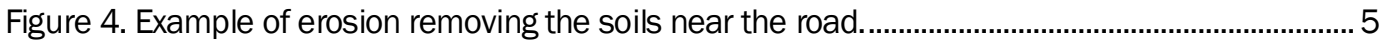

Figure 5. Building a road using manual labor (Afghans)................................................................. 6

Figure 6. Top and bottom pictures are example of vandalism of construction equipment

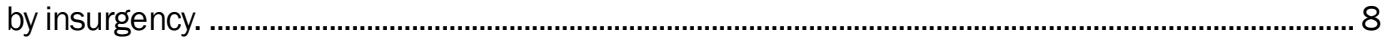




\section{Preface}

This report was prepared by Rosa T. Affleck, Force Projection and Sustainment Branch, Cold Regions Research and Engineering Laboratory (CRREL), U.S. Army Engineer Research and Development Center (ERDC), Hanover, NH; and Dr. Reed Freeman, U.S. Army Engineer District, Afghanistan.

Funding for this study was provided by the U.S. Army Corps of Engineers (USACE) Headquarters, Washington DC.

The authors would like to thank all the USACE staff who shared technical insights and their experiences from working in Afghanistan and Iraq including J ames Wang, Sheryl Lewis, and J ulio Arocho. The authors appreciate the support from Dr. Barbara Sotirin and Dr. Robert Davis for their encouragement and making the opportunity possible. The authors acknowledge the influence of the late Dr. Vincent J anoo, who was an instrumental engineer and a proponent to the reconstruction effort in Afghanis$\tan$.

Excellent review comments were provided by Dr. Sally Shoop and Peter Seman (both from ERDC-CRREL).

The report was prepared under the general supervision of J ames Buska, Chief, Force Projection and Sustainment Branch; Dr. J ustin B. Berman, Research and Engineering Division Chief; Dr. Lance D. Hansen, Deputy Director; and Dr. Robert E. Davis, Director, CRREL.

Colonel Gary E. J ohnston was Commander and Executive Director of ERDC. Dr. J effery P. Holland was ERDC Director. 


\section{Nomenclature}

$\begin{array}{ll}\text { BRD } & \text { Bureau for Reconstruction and Development of Afghanistan } \\ \text { CONUS } & \text { Continental United States } \\ \text { CRREL } & \text { Cold Regions Research and Engineering Laboratory } \\ \text { NATO } & \text { North Atlantic Treaty Organization } \\ \text { QA/ QC } & \text { Quality Assurance/ Quality Control } \\ \text { SIGAR } & \text { Special Inspector General for Afghanistan Reconstruction } \\ \text { TAC } & \text { Transatlantic Programs Center } \\ \text { UROC } & \text { USACE Reachback Operations Center } \\ \text { U.S. } & \text { United States } \\ \text { USACE } & \text { U.S. Army Corps of Engineers } \\ \text { USACE-AED } & \text { U.S. Army Corps of Engineers-Afghanistan Engineer District } \\ \text { USACE-ERDC } & \text { U.S. Army Corps of Engineers-Engineer Research and } \\ \text { USAID } & \text { Development Center }\end{array}$




\section{Objective}

There is a need to close the existing gap between the expectation of applying traditional U.S. engineering and construction standards to projects in places like Iraq, Afghanistan, and other countries. The constraints imposed by "real world" conditions must be faced in those locations. To address this problem, engineering solutions for infrastructure that are site adaptable and scalable need to be developed by making maximum use of locally available resources that are suitable to the local terrain and climate. Involving the host country and locals so that they have a sense of ownership during the design and construction process is key for sustainable infrastructure. This gives the local residents the responsibility for maintaining the long-term performance of their facilities. A more deliberate and holistic approach is needed that considers and integrates the host country's capabilities and adapts to the host country's limitations.

For Afghanistan, the primary problems are poorly documented design and construction standards, as well as a short supply of fundamental engineering knowledge among Afghans. Helping the new Afghan engineers and practitioners in the development of their design and construction standards, transferring and sharing with them the fundamental engineering knowledge, and teaching them how to maintain the infrastructure will begin a positive process to rebuild of their region and the entire country. Thus, the Afghans will acquire engineering capability and ownership in their infrastructure.

The local customs and culture in Afghanistan are very different compared to the U.S. Taking the local socioeconomic conditions and availability of local materials into account will help the sustainability of the infrastructure. Considering the local culture and incorporating local construction knowledge that can impact honor are important in gaining respect from the Afghans. Thus, cultural-sensible facilities should be a part of design and construction process to have the infrastructure being built matter to the Afghans. 


\section{Background: Specific Technical Issues}

Afghanistan has endured a continuous state of conflict for the last 30 years. This started with the Soviet invasion and occupation in 1979, then the Civil War from 1989 to 2001, and followed by the U.S. invasion after the 11 September 2001 terrorist attacks. The current war led by the NATO coalition is building capacity (governance, security, education, and reconstruction). The U.S. reconstruction effort in Afghanistan has been substantial, in the range of $\$ 50$ billion (SIGAR 2010). The reconstruction projects include police and army facilities, schools, clinics, hospitals, and roads.

Afghanistan has graduated only a few engineers in the past 35 years, and some of these engineers often lack knowledge considered basic in Western education (Sargand 2009). Some universities in Afghanistan have just begun to slowly develop their engineering departments. The specific issues identified below are some examples encountered on construction projects in Afghanistan. However, most of these problems are also common in all war-torn and developing countries or states.

\subsection{Physical Environment}

There is a general lack of records and understanding of the physical environment, weather, terrain, environmental processes (frost, floods, droughts, etc.), and seasonal effects that impact infrastructure (Eriksson et al. 2009) in Afghanistan. A substantial portion of the construction must be executed in remote locations (deserts, mountains) that experience weather extremes (hot and cold, wet and dry).

\subsection{Terrain}

Remote mountainous terrain and high elevations conspire to create austere working and living conditions. Existing trails are found in Afghanistan along the edges of the mountain cliffs (Fig. 1). These trails were primarily used for foot or livestock traffic. As roads are needed and being planned for Coalition Forces' use, these trails are considered to be the best routes. These roads are typically narrow (Fig. 2), and have a tendency to experience rock slides because of limited slope stability considerations during construction. Roads become impassable because of rock slides, which are a typical for steep mountainous areas. While roads are planned and constructed, the lack of resources at remote locations makes it difficult to de- 
liver quality construction materials for durable, long-term infrastructure solutions (Eriksson et al. 2009; Freeman 2008).

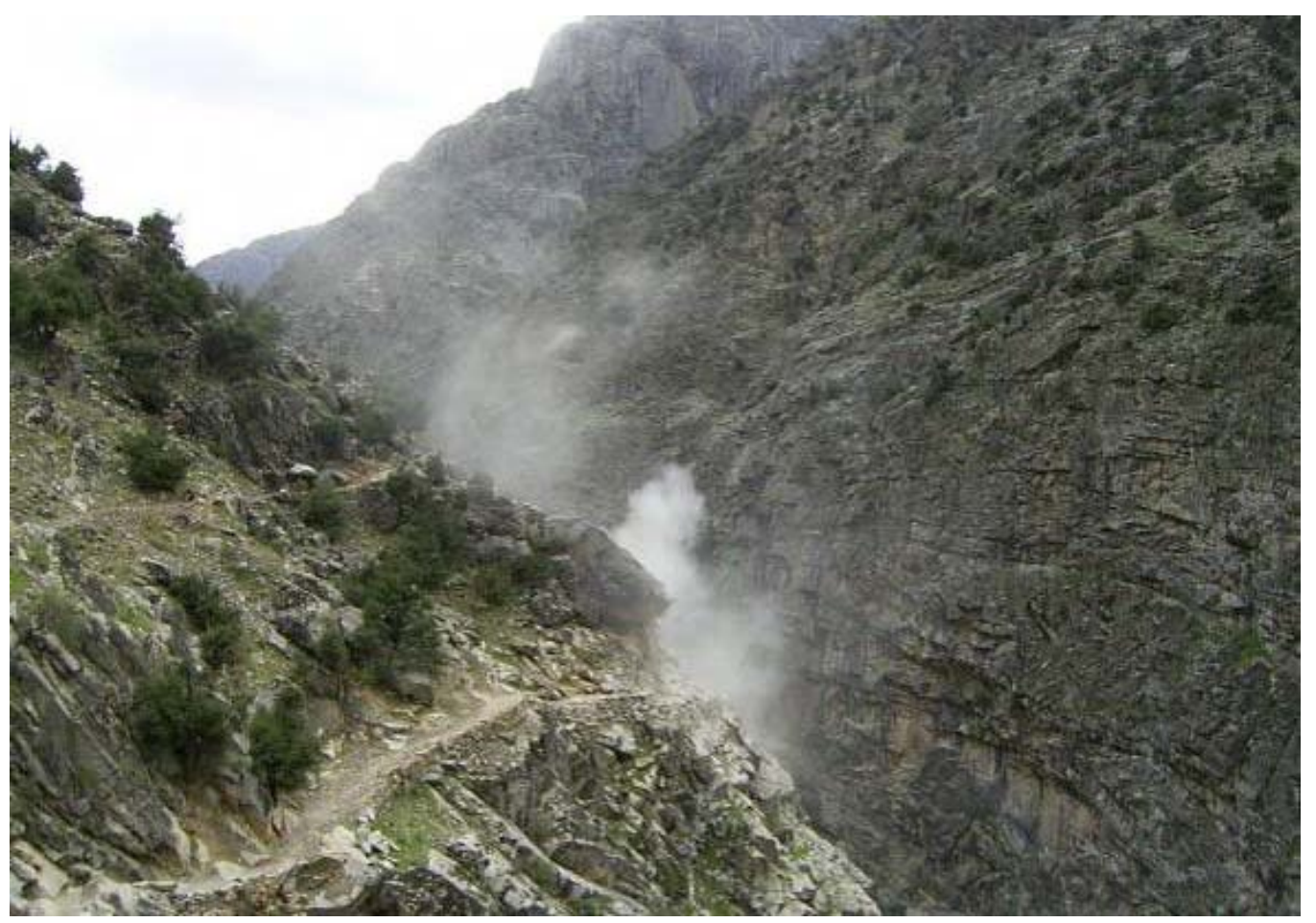

Figure 1. Trails are common in mountainous remote areas in Afghanistan.

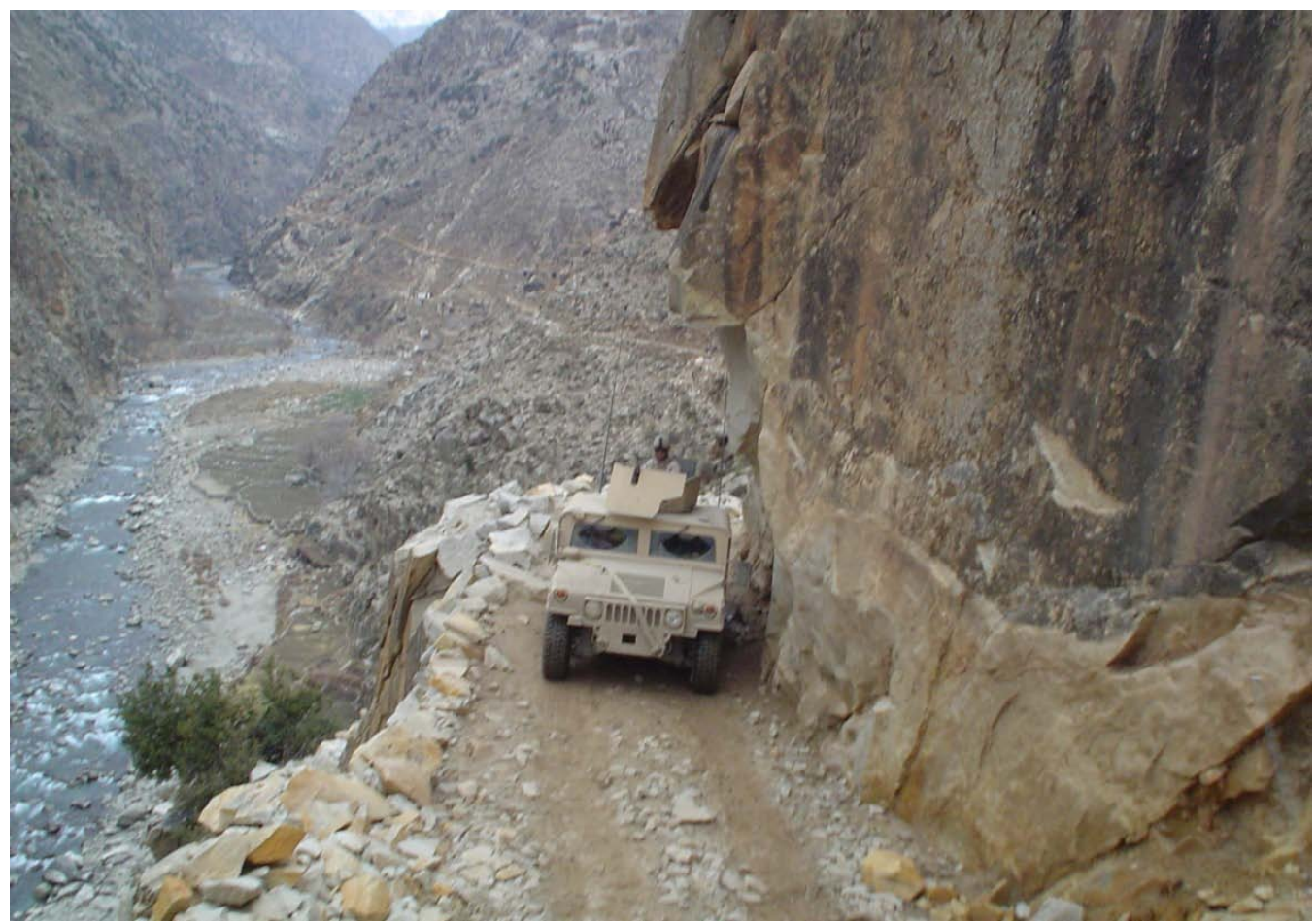

Figure 2. Roads used by U.S. forces. 


\subsection{Erosion}

Heavy rains in the wet season, spring thaws, and violent storms - all made more severe by climate change - are formidable challenges to constructing sustainable infrastructure (Eriksson et al. 2009). During the spring thaw, there is a significant amount of water in low-lying areas (near rivers) from the snowmelt; it is common to have erosion problem in these areas (Fig. 3). In addition, poor soils such as silts and sandy clays are susceptible to erosion and make for extremely difficult roadway base or foundation materials (Freeman 2008). Extreme flow events erode the soils and can create significant ground disturbances near critical infrastructure (Fig. 4).

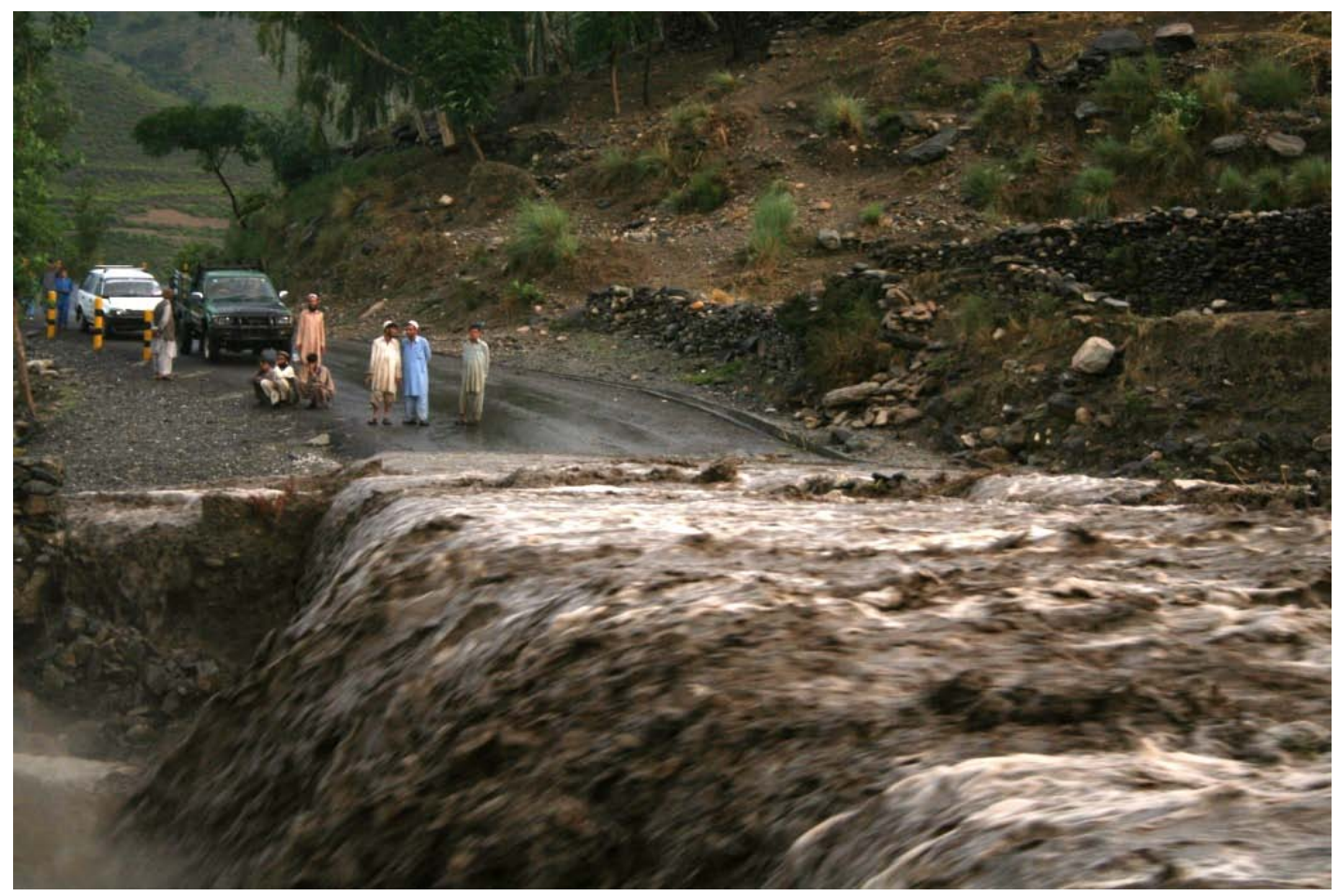

Figure 3. Road washed out during the wet season. 


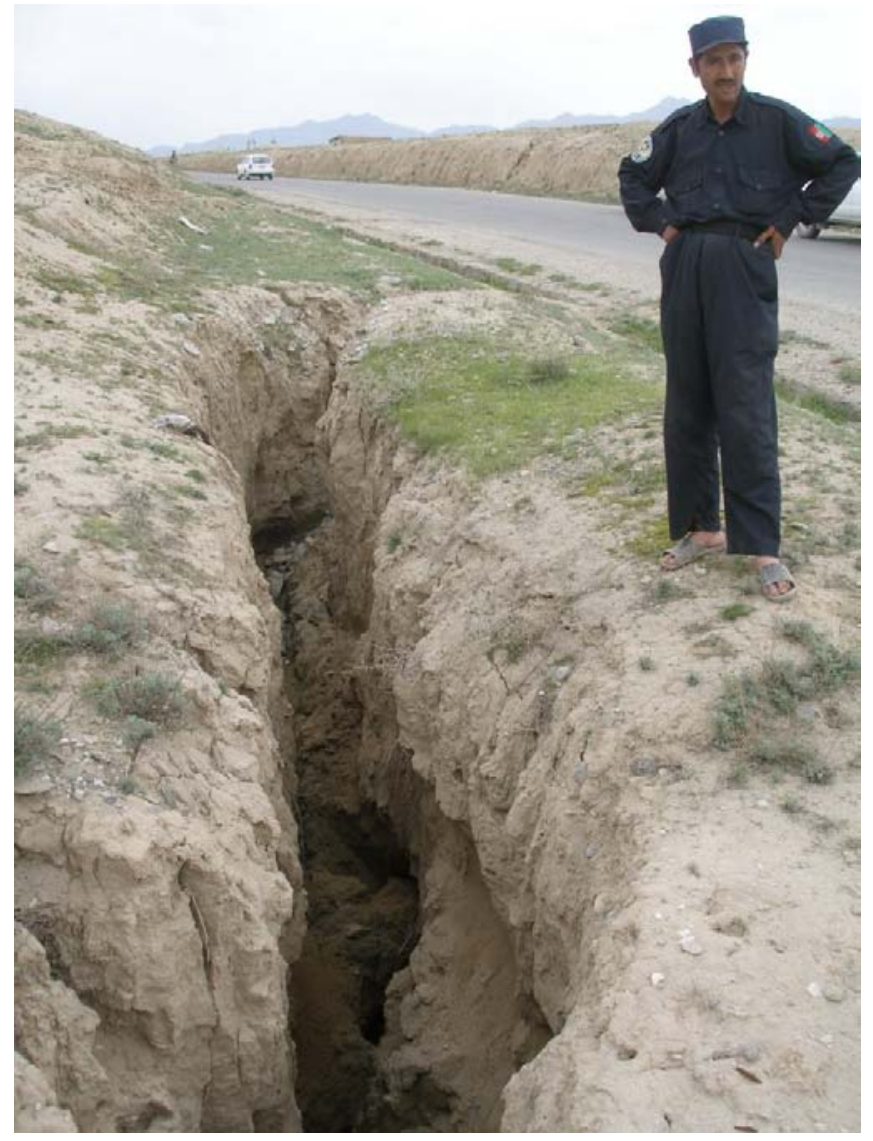

Figure 4. Example of erosion removing the soils near the road.

\subsection{Construction standards}

There is a wide range of construction practice (e.g., building a dwelling) in Afghanistan because of a wide-ranging cultural diversity. Buildings, especially in rural areas, are typical constructed by their inhabitants and not by construction builders or a specialist (Barfield 2010). The Afghan construction methods are parochial and limited to various regions and villages. The common local materials are adopted and used in the construction.

The application of U.S. construction standards is often impossible, especially in remote areas of Afghanistan. Construction equipment in these areas is not yet modernized, and in some cases the logistics of bringing modern equipment to remote provinces are difficult. Labor or trade skills among the local population are rudimentary (Fig. 5). It may be feasible to use local labor with rudimentary tool and equipment; however, the projects will take time to finish. This would be difficult to implement for U.S. projects as construction is driven by deadlines. 


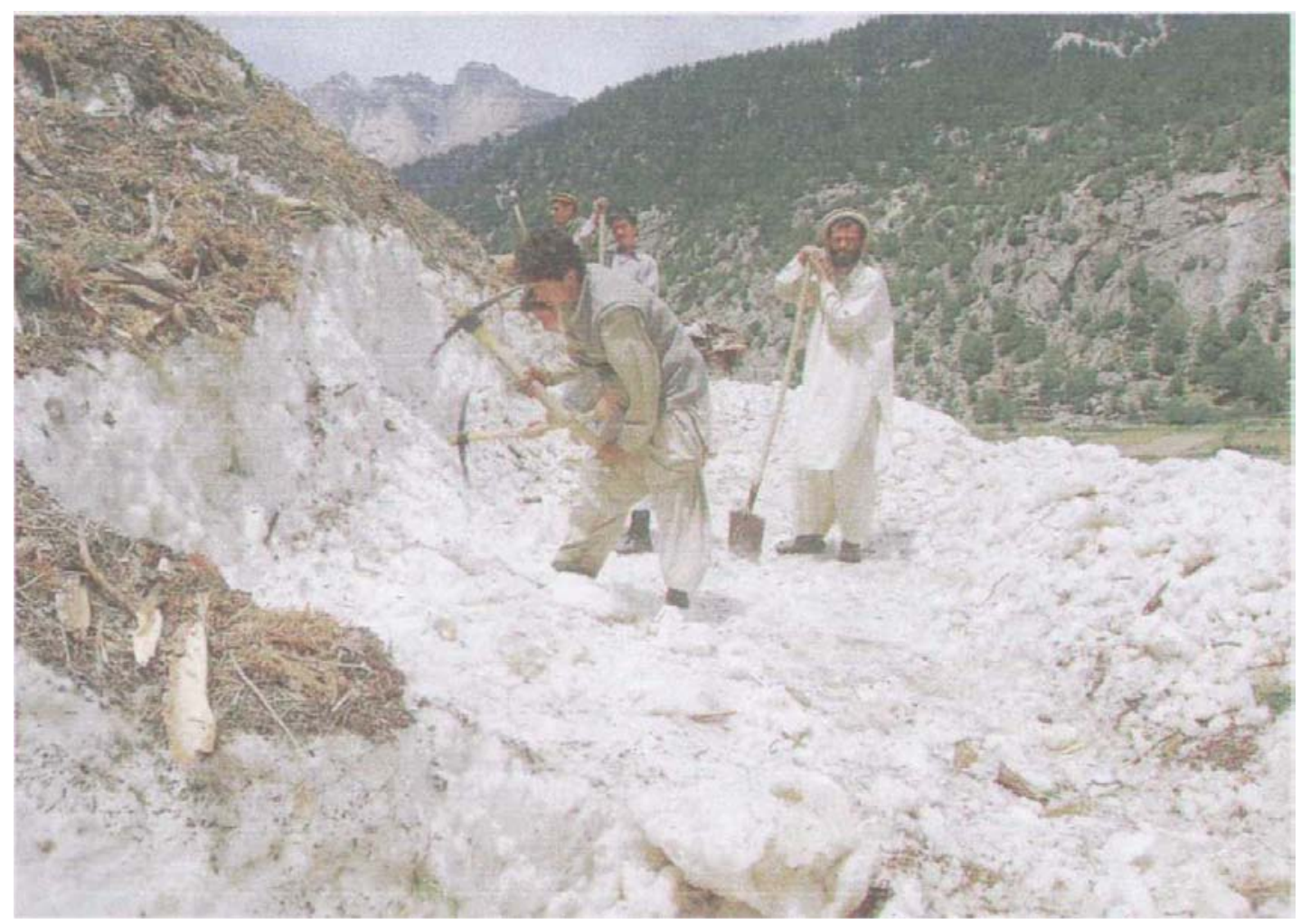

Figure 5. Building a road using manual labor (Afghans).

\subsection{Brain drain}

Afghans generally lack education in engineering, geology, and construction management. It is estimated that approximately 6 million Afghans have left the country since the Russian invasion in 1979 (Braakman 2005). The Afghan emigrants are slow to return (many will not); thus, it will fall on the international community and training programs to fill engineering and construction knowledge gaps.

\section{6 "Tribal" sociological structure}

Afghans have remained "tribal," meaning that citizens living in different provinces can have different cultures and even different languages. The continuance of the tribal nature of this country is largely the result of poor communications and poor transportation infrastructure. For construction, this means that Afghans in different provinces will have different skills and different expectations for structures. In addition, the Afghans in a particular province will be more accepting toward, and even protect, a contractor from their own province. 


\subsection{Difficulties in reaching projects for Quality Assurance/Quality Control (QA/QC) inspections and oversight}

Many projects take place in locations that are too remote or dangerous (or both) for either military or civilian engineers to conduct site visits (Diderich 2007). Thus, projects suffer from a lack of oversight. New engineering methods that are consistent with available materials, labor, and equipment can ensure a quality result with less of a need for on-site supervision. U.S. Army Corps of Engineers-Afghanistan Engineer District (USACE-AED) has recently involved Afghans in QA/ QC inspections, attaining positive results. However, USACE-AED personnel must dedicate time for training and mentoring (Freeman 2008). In addition, another major problem is the short project development cycle and the mission imperative to move forward (Arocho 2009). Any USACE program aimed at improving construction quality and project completion in a combat environment must recognize this reality. Therefore, approaches for strategic design and planning that can be successful under the short-duration project schedules must be developed and used.

\subsection{Security considerations and strategic design for construction}

Many construction activities take place in combat zones that pose significant security risks for the contractors, laborers, and users (USAID 2005). Security and safety of construction personnel must be incorporated into the planning process. Access to the proposed projects to assess the site conditions for design is limited in some cases and requires coordination with military and security support. Even with careful planning, construction materials and equipment are stolen and vandalized, causing project delays (Fig. 6) because of insurgency. 

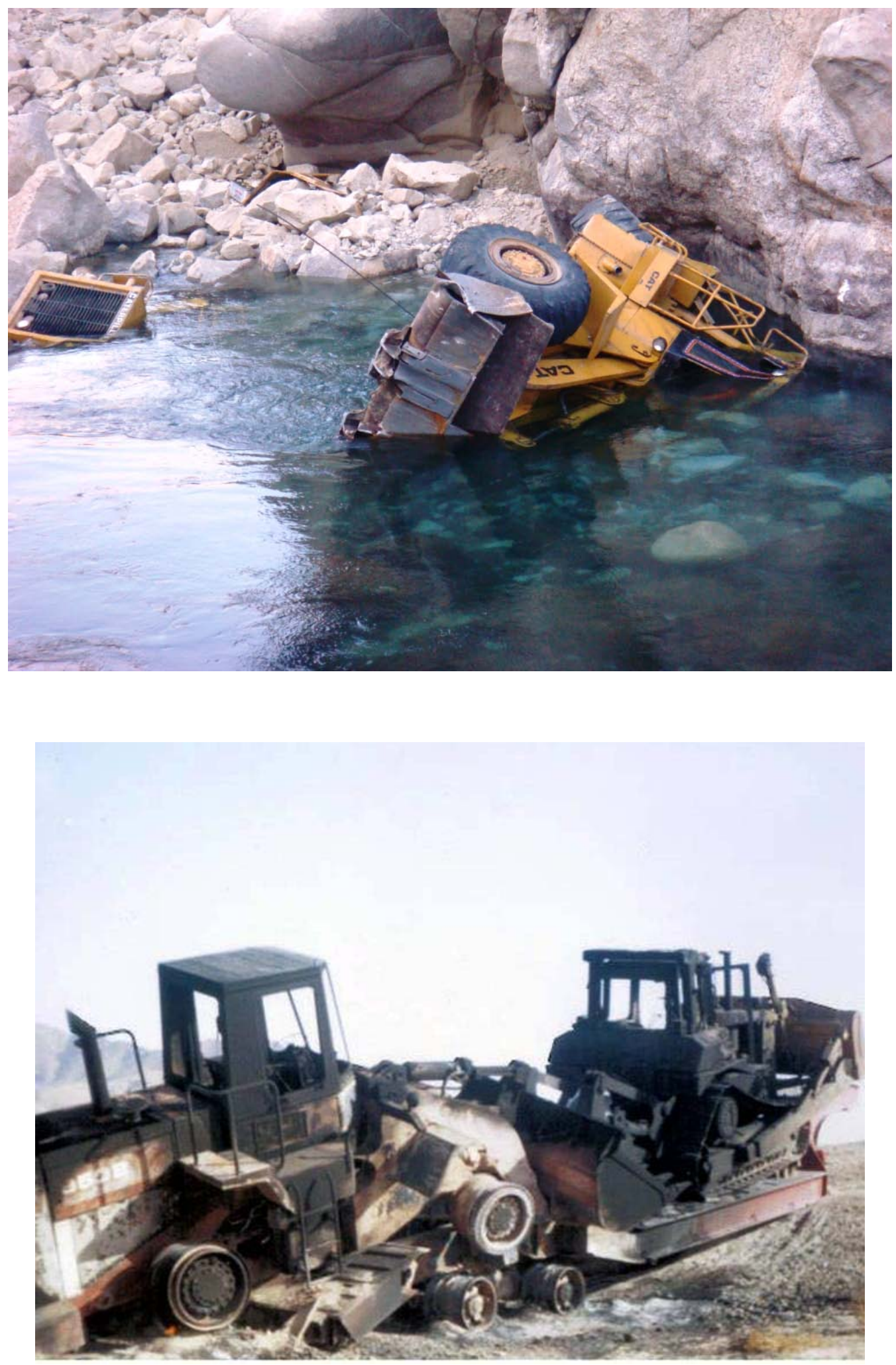

Figure 6. Top and bottom pictures are example of vandalism of construction equipment by insurgency. 


\subsection{Design-build challenges}

Design-build solutions are usually driven by a very tight timeline. Designbuild is a construction project delivery system where the design and construction aspects are performed under one single contract. This system of project delivery is very common in the U.S. because the country has modern capacity and technical capability. With its cultural differences, insurgency, and shortage of skilled labor and management, Afghanistan's capacity to conduct construction and development projects is severely constrained and quite challenging (Silver 2003; BRD 2009). Thus designbuild solution is difficult to implement in Afghanistan.

\subsection{Construction materials}

A lack of reliable transportation networks compounds the problem of delivering required high-quality materials to remote locations. There is a general lack of availability of supplies, such as cement for concrete production, and there is an inconsistency among the suppliers. In addition there is extreme disparity among contractors using inconsistent materials and their construction knowledge (Freeman 2008). Properties of local materials have yet to be attained and tested and some of the materials used are marginal. There are ample supplies of gravel and sand in Afghanistan. At times, river gravel is used as base course material for road construction. However this is not the correct material to use because the edges are rounded; the appropriate gravel for road base course is crushed stones with angular shape. Counterfeit construction materials (e.g., electrical supplies) are common and these materials can have different specifications from what is expected.

\subsection{Information flow}

The U.S. military and civilian engineering and construction staff have deployed and redeployed since the reconstruction and stabilization effort began in Afghanistan. Issues with discontinuity of information occur as staff departs and new staff is assigned to the job. A significant amount knowledge and experience accumulates and the wealth of information must be gathered for in-theater best practices. For example, lessons learned can be disseminated to provide insight for incoming staff and used as input into a planning process for projects. 
In Afghanistan, capacity development (transfer of information and knowledge) is essential to mentor and train local engineers and construction practitioners. Capacity development is extremely difficult without adequate U.S. staffing and time. Recent efforts to address capacity development to employ local nationals and provide training have slowly expanded at various agencies. Transferring of information and knowledge to develop the local population's capacity to sustain and maintain the infrastructure is crucial part of reconstruction and stabilization effort. Better methods of information flow and dissemination of knowledge can positively affect all of these challenges. 


\section{Importance}

Infrastructure, to include transportation, buildings, and water, is very important to national stability and sustaining military operations whose goals are stability, security, and peace-keeping. In addition, infrastructure is the key component for transport capacity and economic development for a war-torn country. The current Department of Defense objective in Afghanistan includes, but is not limited to, marginalizing the insurgency and increasing economic capacity. The coalition forces are working side by side with the Afghan forces to develop the country's capability (governance, economics, infrastructure, etc.). The effort is enormous and includes mentoring and training.

Helping the new Afghan engineers and local practitioners in the development of their design and construction standards, transferring and sharing with them the fundamental engineering knowledge, and improving their understanding of what it takes to maintain the infrastructure will help them rebuild their region and the entire country. Thus, local engineering capability will be developed and Afghans will take ownership of their own infrastructure. As the international forces depart Afghanistan, they must leave behind transportation, building, and water, and other infrastructure that the host country will be capable of managing and maintaining. This is essential for the host country's economic stability, sustainability and growth. 


\section{Approach}

We must begin by establishing design, construction, and maintenance guidance for Afghanistan with social, cultural, and environmental considerations. This must be based on existing lessons learned in-country from both local and international engineering knowledge and experience. Then this knowledge must be transferred to new Afghan engineers and local practitioners. Ultimately, training will promote the Afghans' sense of ownership and ensure future sustainable maintenance. The process of gathering lessons learned and developing tools for use in Afghanistan are:

a. Gather local construction knowledge and existing indigenous examples of sustainable infrastructure by collaborating with local experts and Afghan universities.

b. Compile current in-theater best engineering practices and "lessons learned" by acquiring information on construction projects conducted by U.S. military and civilians, non-governmental organizations, and contractors.

c. Identify and apply "best practices" and methods to fill the gap between traditional U.S. construction standards and Afghan conditions by merging local and cultural practices with U.S. and international methods.

d. Establish adaptable engineering design and construction standards for local infrastructure by developing guidelines with cultural and local consistency and acceptance. The new Afghan standards will be adaptable to different locations within Afghanistan, at a provincial or regional level.

e. Develop and deploy experienced-based training for the Afghan engineers and local construction practitioners. Provide training materials that are tailored to the level of knowledge and communication capability, and the technology capacity of the local populations. For example, at the university level, a training toolkit can have comprehensive information in various forms, including a library of DVD media for live or web-based supporting materials focused on engineering best engineer- 
ing practice and QC/QA. The training tools will be widely disseminated through the partnership with new Afghan engineers and Afghan universities in collaboration with USACE-AED.

f. Capitalize on existing regional partnership programs developed and supported by USACE and other U.S. entities that provide annual training to countries such as Pakistan, Kazakhstan, Kyrgyzstan, etc., for building engineering capability. Regional partnership programs need to include Afghanistan, thus creating a much needed link to provide the engineering training tools for the Afghans.

As Afghanistan is environmentally and culturally diverse, the guidelines for various types and aspects of infrastructure (i.e., roads, buildings, water, electricity, etc.) should primarily focus at the regional or provincial level. The critical infrastructure will be developed with social, cultural, and local consistency and acceptance. 


\section{Coordination}

USACE has successfully supported the Combatant Commands for engineering solutions by managing both engineering and construction projects, environmental restoration, and other projects. USACE leads the full spectrum of national and worldwide projects and programs for planning and implementing capacity development processes (USACE 2008, 2009); this aligns with the development of Readiness XXI Operational Capability (USACE 2007). USACE may be the organization best poised to develop the necessary adaptable standards, given that USACE has extensive knowledge and expertise in construction-related technology and issues in the U.S. (Miles 2007).

The USACE-ERDC possesses a unique combination of basic research and applied engineering expertise that collectively can solve challenging infrastructure problems. USACE-ERDC's researchers and engineers are field capable, having conducted projects on every continent, and are experienced in providing unique, adaptable solutions in austere locations with limited resources. The following items map out a concept for addressing engineering solutions, knowledge gaps, and capacity development in construction, reconstruction, and economic stabilization efforts:

a. Currently, USACE-ERDC's capability for social and cultural assessment has been focused on "in-theater" capacity, building on governance and policies and the counterinsurgency mission. This capacity can be implemented to promote a "common thread" of research and development expertise with capability to unite multiple aid sources and provide them all with uniform best practices.

b. USACE has partnered with several U.S. and international universities. These universities have engineering faculties that have connections in Afghanistan, are Afghans, and have Afghan student programs. This is the best way to expand the engineering capabilities of these Afghans as they return to faculty positions at various universities in Afghanistan.

c. This effort requires coordination with USACE-AED to support and complement their technical objectives, such as quality control and training local populations. 
d. Also the USACE Transatlantic Programs Center (TAC) should promote the Field Force Engineering and the Reachback Operations Center (UROC) functions to leverage and engage support from USACE-ERDC capabilities.

The regional partnership program supported by USACE needs to be expanded to include Afghanistan. This will improve the Afghan engineering capabilities and promote collaboration with neighboring countries. 


\section{The Way Forward}

For Afghanistan, there is a need to integrate sustainable infrastructure planning, development, and construction with social and cultural influences, and to transfer fundamental engineering knowledge. This should start with gathering lessons learned from Afghanistan. The key is to develop local guidance with environmental and cultural sensitivity. Establishing local design, construction, and maintenance standards is essential for sustainable infrastructure and to help the local residents take responsibility for maintaining their infrastructure over the long term. As the international community departs Afghanistan, they must leave behind transportation, buildings, and water infrastructure that the local engineers and practitioners understand and are capable of managing and maintaining.

The process of developing local, culturally appropriate, feasible design, construction, maintenance standards, and guidance is a very large and complex undertaking. The process has yet to be established and embraced by the community of practice and decision makers. However, the first step is to examine the lessons learned from the community of practice in Afghanistan. In addition to incorporating other critical information, input from local nationals should be given high consideration as part of the process for developing the standards and guidance.

Adaptable standards and guidance for each specific region is practical in Afghanistan. This means that the design and construction parameters are limited to certain performance criteria (for example, 10-year building design life) using local or regional materials (possibly of marginal material quality), rudimentary labor, and low-tech equipment. The challenges are to make these standards robust for diverse situations, with flexibility to meet a construction schedule. Adaptable standards and guidance will be likely to produce sensible and sustainable infrastructure for the country. 


\section{References}

Arocho, J . 2009. Personal communication regarding engineering challenges in Iraq. 19 March 2009

Barfield, T. 2010. Afghanistan. Princeton University Press

Braakman, M. 2005. Roots and routes: Questions of home, belonging and return in an Afghan diaspora. M.A. Thesis. The Netherlands: Leiden University.

BRD. 2009. Sustainable development through capacity building: Context and challenges. Bureau for Reconstruction and Development (BRD) of Afghanistan www.brd.org.af (accessed August 2009).

Diderich, J . 2007.The challenges of rebuilding Afghanistan. The Maple Leaf, 10(38).

Eriksson, M., X. Jianchu, A. B. Shrestha, R. A. Vaidya, S. Nepal, and K. Sandistrom. 2009. The changing Himalayas: Impact of climate change on water resources and livelihoods in the Greater Himalayas. Nepal: International Centre for Integrated Mountain Development.

Freeman, R. 2008. Challenges of road construction in Afghanistan. Transportation Systems 2008 Workshop, 21-24 April, Phoenix, AZ.

Miles, S. R. 2007. Reconstruction under adversity rebuilding Iraq: Lessons for the future. USAWC Strategy Research Project. Carlisle Barracks, Pennsylvania: U.S. Army War College.

Sargand, S. 2009. Personal communication regarding on challenges and training of new Afghan engineers. June 2009

Silver, S. 2003. Design-builders pass muster in Afghanistan. www.designbuild.construction.com (accessed March 2009).

Special Inspector General for Afghanistan Reconstruction (SIGAR). 2010. Quarterly report to the United States Congress. Arlington, VA, 30J anuary, 2010 http://www.sigar.mil/reports/quarterlyreprots/Default.aspx

USAID. 2005. Presidential initiatives: Afghanistan road. www.usaid.gov (accessed February 2009).

U.S. Army Corps of Engineers (USACE). 2007. Readiness XXI implementation. USACE Operations Order 2007-09.

U.S. Army Corps of Engineers (USACE). 2008. Capacity development white paper. HQUSACE, CEMP-GR.

U.S. Army Corps of Engineers (USACE). 2009. Capacity development -international. HQUSACE, CEMP-MP, Engineer Pamphlet EP 5-1-1. 


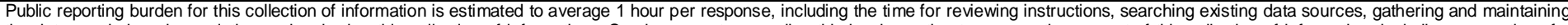

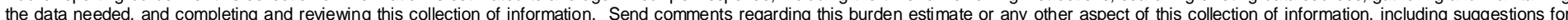

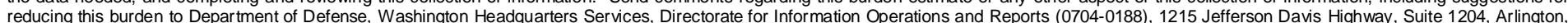

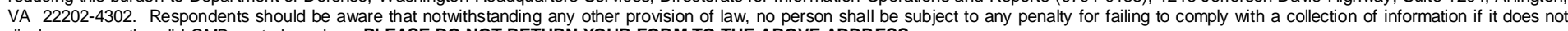
display a currently valid OMB control number. PLEASE DO NOT RETURN YOUR FORM TO THE ABOVE ADDRESS.

\begin{tabular}{l|l} 
1. REPORT DATE (DD-MM-YYYY) & 2. REPORT TYPE
\end{tabular}

November 2010

\section{TITLE AND SUBTITLE}

Challenges for Engineering Design, Construction, and Maintenance of Infrastructure in Afghanistan

3. DATES COVERED (From - To)

5a. CONTRACT NUMBER

5b. GRANT NUMBER

5c. PROGRAM ELEMENT NUMBER

6. AUTHOR(S)

5d. PROJECT NUMBER

Rosa T. Affleck and Reed Freeman

5e. TASK NUMBER

5f. WORK UNIT NUMBER

\section{PERFORMING ORGANIZATION NAME(S) AND ADDRESS(ES)}

8. PERFORMING ORGANIZATION REPORT NUMBER

Cold Regions Research and Engineering Laboratory

U.S. Army Engineer Research and Development Center

72 Lyme Road, Hanover, NH 03755

Special Report 10-2

U.S. Army Engineer District, Afghanistan

Qalaa House, Kabul, Afghanistan

9. SPONSORING I MONITORING AGENCY NAME(S) AND ADDRESS(ES)

10. SPONSOR/MONITOR'S ACRONYM(S)

U.S. Army Corps of Engineers

Washington, DC 20314-1000

11. SPONSOR/MONITOR'S REPORT NUMBER(S)

\section{DISTRIBUTION / AVAILABILITY STATEMENT}

Approved for public release; distribution is unlimited

\section{SUPPLEMENTARY NOTES}

\section{ABSTRACT}

Western nations, particularly the United States, may not have the most applicable construction techniques for rebuilding infrastructure in other countries. Afghanistan, for example, does not have well-documented engineering design and construction standards. The U.S. forces and Government agencies arrived in Afghanistan anticipating that construction funded by the U.S. would meet the Continental United States (CONUS) level of standard practice. Similarly, other well-developed countries arrived in Afghanistan with the intention of using their country's adopted construction standards. Both U.S. and international construction standards may appear logical to use for this purpose. However, it is often difficult, and many times impossible, to meet traditional U.S. engineering design and construction standards in post-conflict areas owing to limitations that include: a scarcity of high-quality materials and construction equipment, a lack of understanding of the terrain and environment, a lack of awareness of available local skills, a lack of skilled labor, and poor socio-economic conditions. A more deliberate and holistic approach is needed in which we consider and integrate the host nation's capabilities and understand their limitations. The majority of infrastructure projects in post-conflict countries are mission-specific. In most cases, once constructed and operational, very little emphasis is given addressing maintenance issues. Site-specific and culturally sustainable guidance for maintenance must be implemented as a part of the design process and incorporated into training programs to ensure sustainable, long-term performance or service life of the infrastructure. This ensures leaving behind transportation, buildings, water, and other infrastructure that the host country is capable of managing and maintaining.

U.S. Army Corps of Engineers (USACE) has successfully supported the Combatant Commands for engineering solutions by managing both engineering and construction projects, environmental restoration, and other projects. The USACE Engineer Research and Development Center (ERDC) possesses a unique combination of basic research and applied engineering expertise that collectively can solve challenging infrastructure problems. USACE-ERDC's researchers and engineers are field capable, having conducted projects on every continent, and are experienced in providing unique, adaptable solutions in austere locations with limited resources.

$\begin{array}{lll}\text { 15. SUBJECT TERMS } & \text { Design standards } & \text { Sensitivity to local culture } \\ \text { Afghanistan } & \text { Infrastructure } & \text { USACE-ERDC } \\ \text { Construction standards } & \text { Limits in socio-economic conditions } & \text { USACE mission }\end{array}$

Limits in socio-economic conditions

16. SECURITY CLASSIFICATION OF:

a. REPORT

Unclassified OF ABSTRACT

18. NUMBER OF PAGES

c. THIS PAGE

Unclassified

Unclassified
27 19a. NAME OF RESPONSIBLE PERSON

19b. TELEPHONE NUMBER (include area code) 